\title{
Research Paper: Effects of Isoniazid on Tolerance and Sensitization to the Rewarding Properties of Morphine: A Conditioned Place Preference Procedure Investigation in Mice
}

\author{
Amir Abbas Barzegari ${ }^{1 *}$ (D), Kamran Shahabi ${ }^{1}$ iD
}

1. Department of Biology, Faculty of Basic Science, University of Maragheh, Maragheh, Iran.

\begin{tabular}{|l|l|}
\hline $\begin{array}{c}\text { Use your device to scan } \\
\text { and read the article online }\end{array}$ & $\begin{array}{l}\text { Crtation: Barzegari, A. A., \& Shahabi, K. Effects of Isoniazid on Tolerance and Sensitization to the Rewarding Properties of } \\
\text { Morphine: A Conditioned Place Preference Procedure Investigation in Mice. Basic and Clinical Neuroscience, 11(4), 481-490. } \\
\text { http://dx.doi.org/10.32598/bcn.11.4.1940.1 }\end{array}$ \\
dolo & http://dx.doi.org/10.32598/bcn.11.4.1940.1
\end{tabular}

\section{(c) (1) (8)}

Article info:

Received: 13 Jul 2019

First Revision: 25 Jul 2019

Accepted: 02 Dec 2019

Available Online: 01 Jul 2020

Keywords:

Isoniazid, Morphine,

Conditioned place preference,

Tolerance, Sensitization,

Reward

\section{ABS T RACT}

Introduction: The GABAergic system of the brain plays a key role in morphine tolerance and sensitization. As isoniazid is a modulator of the GABAergic system, the present study aims to understand whether isoniazid can influence the induction of tolerance and sensitization to the rewarding effects of morphine.

Methods: The rewarding effects of morphine and isoniazid were assessed using a Conditioned Place Preference (CPP) procedure in female mice. Tolerance to the rewarding effects of morphine was induced with high-dose morphine $(25 \mathrm{mg} / \mathrm{kg}, \mathrm{SC})$, twice a day, for four days. Also, the sensitization was induced with an effective dose of morphine $(5 \mathrm{mg} / \mathrm{kg}$, SC), once a day, for three days. During the induction of tolerance or sensitization, the different groups of mice received saline or isoniazid $(25,50$, and $75 \mathrm{mg} / \mathrm{kg}$, IP) one hour before each morphine injection.

Results: Morphine $(0.5-10 \mathrm{mg} / \mathrm{kg}, \mathrm{SC})$ produced a significant CPP, but isoniazid $(25,50$, and $75 \mathrm{mg} / \mathrm{kg}$, IP) did not induce place preference or place aversion in mice. Although an effective dose of morphine $(5 \mathrm{mg} / \mathrm{kg}$, SC) did not induce CPP in morphine tolerated mice, an ineffective dose $(0.5 \mathrm{mg} / \mathrm{kg}, \mathrm{SC})$ could produce a significant CPP in morphine-sensitized animals. The administration of isoniazid before morphine (on the days of tolerance or sensitization induction) inhibited the development of tolerance or sensitization to the rewarding effect of morphine in the CPP paradigm.

Conclusion: Isoniazid can be a useful drug for the prevention of tolerance and sensitization to the rewarding effects of morphine.

\section{* Corresponding Author:}

Amir Abbas Barzegari, PhD.

Address: Department of Biology, Faculty of Basic Science, University of Maragheh, Maragheh, Iran

Tel: +98 (41) 37278001

E-mail: barzegaridoctora@gmail.com 


\section{Highlights}

- Morphine, but not isoniazid, induced a significant conditioned place preference.

- Isoniazid inhibited the tolerance and sensitization to the rewarding effects of morphine, which was assessed by the conditioned place preference procedure.

- The lowest dose of isoniazid ( $25 \mathrm{mg} / \mathrm{kg}$, IP) was the most effective dose for the prevention of morphine tolerance and sensitization.

\section{Plain Language Summary}

Morphine is an important drug for pain relief. However, this drug influences the brain's reward system and produces rewarding effects. The rewarding effects of morphine are the main reason for its abuse. Also, the repeated administration of morphine can cause sensitization or tolerance to its rewarding effects. The rewarding effects of morphine increase in sensitization. On the contrary, morphine's rewarding effects decrease, when tolerance occurs. Sensitization and tolerance are involved in addiction to morphine. Therefore, it is essential to find new drugs to prevent morphine tolerance and sensitization. Isoniazid is a drug used for the treatment of tuberculosis. By entering the brain, this drug also affects the brain. In this research, the effects of isoniazid on the tolerance and sensitization to the rewarding effects of morphine were evaluated, using a conditioned place preference procedure. This is a simple procedure for evaluating the rewarding effects of drugs, including morphine. The results showed that isoniazid could inhibit the induction of tolerance and sensitization to the rewarding effects of morphine. Therefore, isoniazid may be a good candidate for the treatment of addiction to morphine.

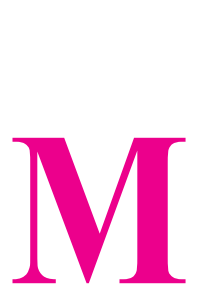

\section{Introduction}

orphine as an opioid has some crucial medical applications, including anesthesia, pain management, and the relief of acute pulmonary edema (Katzung, 2017). However, because of its euphoric effects, morphine abuse has remained a global problem (Compton \& Volkow, 2006; McCabe, West, \& Boyd, 2013; Negus \& Miller, 2014). Prolonged morphine use for medical or recreational purposes can lead to tolerance or sensitization to its analgesic and rewarding effects (Katzung, 2017; Stewart \& Badiani, 1993). The drug tolerance forcefully leads to the increase of drug dosage in order to get the previous pharmacological effects. Tolerance to the rewarding effects of morphine causes morphine-dependent people to take higher doses of this drug to achieve the previously experienced euphoria (Koob \& Le Moal, 2001). Notably, the possibility of tolerance induction to the euphoric or rewarding effects of morphine is high (Katzung, 2017). In other words, the development of tolerance is always a life-threatening risk in opioid-dependent subjects. For example, a high death rate of opioid overdose usually occurs among the former prisoners with opioid tolerance (Binswanger, Blatchford, Mueller, \& Stern, 2013).
Alternatively, using morphine can also result in another problem referred to as sensitization. Since sensitization increases the pharmacological effects of a drug, it can be considered as the opposite of tolerance (Koob \& Le Moal, 2001; Stewart \& Badiani, 1993; Van Ree, Gerrits, $\&$ Vanderschuren, 1999). An ineffective dose of morphine acquires a highly rewarding property when sensitization to the rewarding effects of morphine occurs. Previous studies have shown that an ineffective dose of morphine could induce Conditioned Place Preference (CPP) in morphine-sensitized animals (Azizi, Haghparast, \& Hassanpour-Ezatti, 2009; Sahraei et al., 2006). Also, the role of sensitization in the induction of morphine craving has been established in previous studies. Importantly, evidence indicates that morphine craving may pave the way for the addiction to the drug (Robinson \& Berridge, 1993).

Isoniazid is a derivative of hydrazine; it is a drug of choice as a first-line defense against active and latent tuberculosis (Shi, Itagaki, \& Sugawara, 2007). Apart from its antibacterial effects, this drug can influence the brain by crossing the blood-brain barrier (Nau, Sörgel, \& Eiffert, 2010). For instance, isoniazid had mood-enhancing and euphoric effects on patients with tuberculosis (Lorenz, Calden, \& Ousley, 1953; Salzer \& Lurie, 1953). One of the main mechanisms by which isoniazid influ- 
ences the brain is the modulation of the GABAergic system. Research indicates that isoniazid in high doses decreases the GABA levels of the brain and induces convulsions (Asehinde et al., 2018; Gupta, Dua, Kazmi, \& Anwar, 2014; Patil, Patil, Patil, \& Jadhav, 2011). However, some studies showed that low-dose isoniazid has GABA-elevating effects (Perry \& Hansen, 1973; Perry, Urquhart, Hansen, \& Kennedy, 1974). In this regard, some researchers suggested that isoniazid might be a useful drug for the treatment of Huntington disease (Perry, Wright, Hansen, \& MacLeod, 1979).

CPP is a procedure that has been widely used to assess the rewarding properties of addictive drugs, including morphine (Tzschentke, 1998; Zarrindast \& Rezayof, 2007). Also, this procedure has been used for the evaluation of tolerance and sensitization to the rewarding effects of morphine (Chefer \& Shippenberg, 2009; Sahraei et al., 2006). Drugs affecting the GABAergic system of the brain can modulate the morphine rewarding effects (Tzschentke, 1998; Zarrindast \& Rezayof, 2007). The GABAergic agents can also alter the morphine-induced tolerance and behavioral sensitization (Alavian \& Ghiasvand, 2017; Bartoletti, Ricci, \& Gaiardi, 2007; Fu, Yang, Xiao, Zhao, \& Huang, 2012). As mentioned above, we can consider isoniazid as a GABAergic agent. Hence, the main purpose of the present study was to evaluate the effects of isoniazid on tolerance and sensitization to the rewarding properties of morphine, using a CPP paradigm.

\section{Materials \& Methods}

\subsection{Animals}

In the present study, female NMRI mice within a weight range of 20 to $25 \mathrm{~g}$ at the beginning of the experiments were used. The mice were purchased from the Razi Vaccine and Serum Research Institute (Karaj City, Iran) and transported to the animal house of the University of Maragheh, Maragheh City, Iran. The animals were kept in groups of 10 mice per polycarbonate cage in the vivarium. The vivarium met the standard conditions for keeping the laboratory animals: a light-dark cycle with a $12: 12 \mathrm{~h}$ period (illumination at 7:00 $\mathrm{AM}$ ), the room humidity about $70 \%$, and a temperature of $22 \pm 2^{\circ} \mathrm{C}$. The laboratory animals had free access to the standard rodent food pellets and tap water. The ethical issues were considered in all experimental procedures on laboratory animals. After 10 days of acclimatization, the mice were randomly allocated to different experimental groups of 8 . The animals used in each part of the experiments were naïve.

\subsection{Drugs}

Morphine sulfate ampoules (Darou Pakhsh Pharmaceutical Mfg. Co., Tehran, Iran) and isoniazid powder (Solarbio, China) were used in the experiments. Isoniazid was dissolved in normal saline just before the injections and administered in the doses of 25,50 , and $75 \mathrm{mg} /$ $\mathrm{kg}$. The different doses of morphine $(0.5-10 \mathrm{mg} / \mathrm{kg})$ were prepared by diluting the ampoules of morphine sulfate $(10 \mathrm{mg} / \mathrm{mL})$. The injection volume of isoniazid and morphine was $10 \mathrm{~mL} / \mathrm{kg}$. The mice received morphine Subcutaneously (SC) and isoniazid Intraperitoneally (IP).

\subsection{CPP apparatus}

In the present research, 8 identical CPP apparatus similar to those used by Sahraei's research group (Sahraei et al., 2007) were used. Each apparatus included a rectangular wooden cube $(30 \times 15 \times 15 \mathrm{~cm})$ that consisted of two identical adjacent cubic compartments $(15 \times 15 \times 15)$. One side of the apparatus colored white and the other side black to provide different visual stimuli in two sides. Also, the floors of the two compartments had different textures. The white compartment had a smooth floor, but there was a stainless steel mesh on the floor of the black side. The two compartments were separated with a guillotine door to prevent the free movement of animals between the two parts, in the case of necessity. Whenever it was needed, the guillotine door was removed and the animals were allowed to pass freely between the two parts of the device. Moreover, it was shown in a pilot study that the mice had a relative preference for the black side of the apparatus, thus, a biased CPP procedure was used in our experiments. The animals were conditioned to the non-preferred side of the apparatus (the white part).

\subsection{Place conditioning procedure}

The CPP procedure used in the experiments was similar to that of the Sahraei's procedure with a few modifications (Sahraei et al., 2007). It comprised four consecutive phases lasting six days in each place conditioning period:

1. Adaptation: In this phase, each animal was placed separately in the apparatus for 10 minutes (guillotine door was removed), and had free access to both compartments.

2. Preconditioning: This phase was the same as the previous one. The only difference was the measurement of the time each animal spent in the white compartment with a chronometer. The crossing of mice's forepaws 
and heads from one compartment to the other one was considered as the placement of the animal on that side.

3. Conditioning: This phase consisted of six conditioning sessions (three sessions for saline pairing and three sessions for drug pairing) that were performed during three consecutive days; on each day, two conditioning sessions were conducted at 9:00 AM and 3:00 PM. There was a 6-hour interval between the morning and afternoon conditioning sessions to ensure that the effect of the drug was lost until the second conditioning session. On the conditioning days (days 3-5 of CPP), the two compartments were separated from each other with the guillotine door. On day one, in the morning conditioning session, each animal received the drug (morphine or isoniazid) and was immediately placed into the white compartment for 40 minutes. In the afternoon session, the animals received saline and were confined to the black side of the device for the same period (40 $\mathrm{min}$ ). On day two of the conditioning phase, the order of conditioning session was reverse of the first conditioning day (ie, the animals received saline in the morning conditioning session and experienced the drug's effects in the afternoon conditioning session). Conditioning sessions on the third day were just like the first day of the conditioning phase.

4. Postconditioning or test phase: In this phase, first, the guillotine door was removed. Then, each animal was separately placed in the apparatus for 10 minutes, and the time that each mouse spent in the drug-paired compartment (the white part of the apparatus) was recorded.

The difference of the spent times in the drug-paired compartment (the white part of the device) between the preconditioning and postconditioning phases (the change in preference) was considered as the conditioning score.

\subsection{Methods of morphine tolerance and sensitiza- tion induction}

The methods for the induction of sensitization and tolerance to the rewarding effects of morphine were similar to those used by Sahraei (Sahraei et al., 2006). In a room different from the conditioning room, each animal received an effective dose of morphine $(5 \mathrm{mg} / \mathrm{kg}, \mathrm{SC}$ ) once a day for three consecutive days. The animals were immediately returned to the vivarium after each injection. For the next five days, the animals received no treatment. At last, conditioning procedure began for the ineffective doses of morphine $(0.5 \mathrm{mg} / \mathrm{kg})$, from the ninth day of the experiment, as described before. For tolerance induction, the high doses of morphine $(12.5,25,50 \mathrm{mg} / \mathrm{kg})$ were injected into different groups of animals, twice a day (9:00 AM and 3:00 PM) for four consecutive days. After each injection, the animals were returned to the vivarium. Then, the induction of CPP was begun with the effective dose of morphine $(5 \mathrm{mg} / \mathrm{kg})$, on the fifth day of the protocol.

\subsection{Measurement of locomotor activity}

At the 10-minute sessions of the test day, in addition to the measurement of the time in the drug-paired compartment, the locomotor activity of each animal was recorded. Achieve this, the floor of both sides of the device was divided into four equal square parts with two perpendicular lines (like a plus sign). Each time a mouse crossed a line and entered from one square to another one, one score added to its locomotor activity. The presence of mice's heads and forepaws on each square part considered as the mice's entry to that part.

\subsection{Study design}

Experiment 1: The establishment of a dose-response relationship for morphine and isoniazid-induced conditioned place preference

Six groups of mice received saline (control) and morphine $(0.5,1,2.5,5$, and $10 \mathrm{mg} / \mathrm{kg}, \mathrm{SC})$. The control group was involved in the experiments to ensure that the conditioning schedule or physical effect of injections did not influence the conditioning score. Besides, the different doses of isoniazid $(25,50$, and $75 \mathrm{mg} / \mathrm{kg}$, IP) were administered to three groups of animals to investigate whether isoniazid could induce any CPP or CPA (conditioned place aversion). Here, the control group received saline intraperitoneally.

Experiment 2: The establishment of a dose-response relationship for the induction of tolerance to the rewarding effects of morphine

Four groups of animals received high doses of morphine $(12.5,25$, and $50 \mathrm{mg} / \mathrm{kg}, \mathrm{SC})$ and saline (control), twice a day, for four consecutive days. Next, the induction of CPP was begun with an effective dose of morphine $(5 \mathrm{mg} / \mathrm{kg}, \mathrm{SC})$ on the fifth day of this experiment. This part of the experiments aimed to find the optimum dose of morphine for tolerance induction.

Experiment 3: The effect of isoniazid on the induction of morphine tolerance with the optimum high dose of morphine

During the days of tolerance induction, four groups of animals received saline or isoniazid $(25,50$, and $75 \mathrm{mg} /$ $\mathrm{kg}$, IP), one hour before receiving the high dose of mor- 
phine ( $25 \mathrm{mg} / \mathrm{kg}, \mathrm{SC}$ ). Then, on the fifth day of this experiment, the induction of morphine CPP was commenced with the effective dose of morphine $(5 \mathrm{mg} / \mathrm{kg}, \mathrm{SC})$.

Experiment 4: The effects of isoniazid on the induction of morphine sensitization

During the induction of sensitization, the mice were intraperitoneally treated with the saline or isoniazid doses of 25,50 , and $75 \mathrm{mg} / \mathrm{kg}$, one hour before receiving morphine $(5 \mathrm{mg} / \mathrm{kg}, \mathrm{SC})$. Next, the animals had a five-day interval with no treatment. The induction of CPP for the ineffective dose of morphine $(0.5 \mathrm{mg} / \mathrm{kg})$ was begun by one day following this stage. One hour after receiving the intraperitoneal injections of saline or isoniazid (25, 50 , and $75 \mathrm{mg} / \mathrm{kg}$ ), four other groups of mice were treated with saline $(1 \mathrm{~mL} / \mathrm{kg})$. The purpose was to illustrate that saline could not induce sensitization.

\subsection{Statistical analysis}

The quantitative data, including change in preference (as conditioning score) and the locomotor activity, were expressed as Mean \pm SEM. For revealing any statistically significant difference between different experimental groups, the one-way ANOVA test was conducted in the SPSS V. 18. If the P-value was less than 0.05 , the difference would be considered significant. When the one-way ANOVA showed a significant difference, the LSD post hoc test was performed to compare the control and experimental groups.

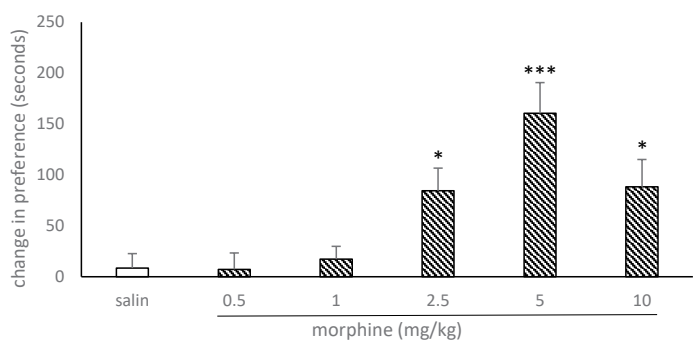

Figure 1A

\section{Results}

\subsection{Morphine dose-response for CPP}

In this part of the experiments, the mice were conditioned with the different doses of morphine $(0,0.5,1$, $2.5,5$, and $10 \mathrm{mg} / \mathrm{kg}, \mathrm{SC}$ ). One-way ANOVA showed a significant difference in the change in preference scores between the saline and morphine-treated animals $\left(\mathrm{F}_{5,42}=8.1, \mathrm{P}<0.001\right)$ (Figure 1A). Among the morphine doses that induced a significant CPP $(2.5,5$, and 10 $\mathrm{mg} / \mathrm{kg}, \mathrm{SC}$ ), $5 \mathrm{mg} / \mathrm{kg}$ dose was the most effective one. Therefore, in the next parts of the research, $5 \mathrm{mg} / \mathrm{kg}$ of morphine was selected as the effective dose of morphine for the induction of CPP. Also, the one-way ANOVA indicated no significant difference in the locomotor activity among the different groups that received the graded doses of morphine and saline $\left(\mathrm{F}_{5,42}=0.4, \mathrm{P}=0.77\right)$.

\subsection{Isoniazid dose-response for CPP}

In this experiment, four groups of mice received saline or isoniazid $(25,50$, and $75 \mathrm{mg} / \mathrm{kg}$, IP) in the conditioning phase of CPP. The one-way ANOVA revealed a significant difference in the conditioning scores among the different groups that received saline and isoniazid $\left(\mathrm{F}_{3,27}=3.7, \mathrm{P}=0.02\right)$ (Figure 1B). However, the post hoc test showed that none of the isoniazid-treated groups significantly differed from the saline-treated group. Moreover, on the test day, a significant decrease in the locomotor activity was observed in isoniazid groups, compared with the saline-treated group $\left(\mathrm{F}_{3,27}=13.5, \mathrm{P}<0.001\right)$.

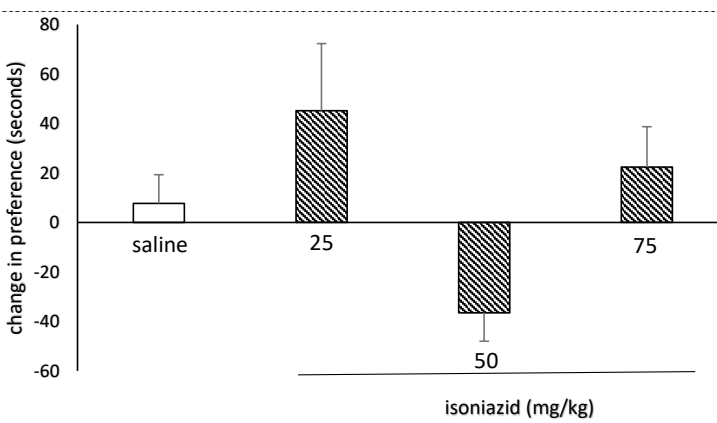

Figure 1B

Figure 1. The one-way ANOVA results

NEUR SCIENCE

A. Effects of Morphine; or B. Isoniazid on the Induction of CPP

Animals received the different doses of morphine $(0.5,1,2.5,5$, and $10 \mathrm{mg} / \mathrm{kg}$, SC) or isoniazid $(25,50$, and $75 \mathrm{mg} / \mathrm{kg}$, IP) in the conditioning phase of the CPP paradigm. The change in preference was calculated for the mice of each group for 10 minutes. Each point shows the Mean $\pm S E M$ of the change in preference for eight mice.

$* \mathrm{P}<0.05 ; * * * \mathrm{P}<0.001$ compared with the saline control group. 


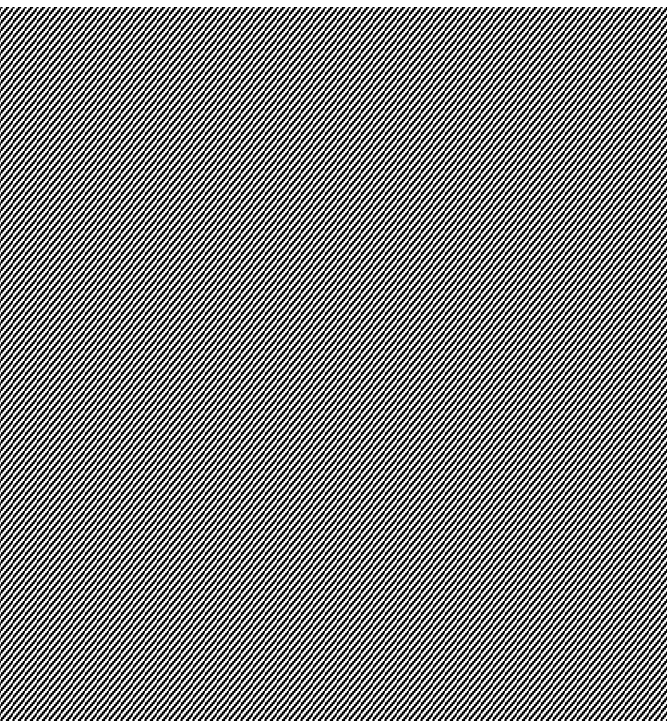

NEUR:SCIENCE

Figure 2. Effects of the Different High Doses of Morphine on the Induction of Tolerance to the Rewarding Effects of Morphine

Three groups of mice received high doses of morphine (12.5, 25 , and $50 \mathrm{mg} / \mathrm{kg}$, SC) twice a day for four days. The induction of CPP was commenced with the effective dose of morphine $(5 \mathrm{mg} / \mathrm{kg}, \mathrm{SC})$ on the fifth day of the experiment. Each point shows the Mean $\pm S E M$ of the change in preference for eight mice;

***P<0.001 compared with the saline control group

3.3. Dose-response effect of morphine on the induction of tolerance to rewarding effects

The administration of the high doses of morphine (12.5, 25 , and $50 \mathrm{mg} / \mathrm{kg}$ ) to the different groups of mice (during tolerance induction) significantly prevented the induction of CPP with the effective dose of morphine $(5 \mathrm{mg} / \mathrm{kg}$, SC) $\left(\mathrm{F}_{3,28}=20.23, \mathrm{P}<0.001\right)$ (Figure 2). Also, the analysis of the locomotor activity on the test day showed a significant difference in the locomotor activity between the mice that received saline and those treated with the high doses of morphine on the days of tolerance induction $\left(\mathrm{F}_{93,28}=5.33\right.$, $\mathrm{P}<0.01)$. The LSD post hoc test indicated that only the highest dose of morphine $(50 \mathrm{mg} / \mathrm{kg}$ ) had a significant effect on the locomotor activity on the test day.

\subsection{Isoniazid effects on the induction of tolerance with the optimum high dose of morphine}

The administration of isoniazid $(25,50$, and $75 \mathrm{mg} / \mathrm{kg}$, IP) one hour before morphine $(25 \mathrm{mg} / \mathrm{kg}, \mathrm{SC})$, during tolerance induction, completely prevented the development of tolerance to the rewarding effects of morphine $\left(\mathrm{F}_{3,24}=23.21, \mathrm{P}<0.001\right)$ (Figure 3). The lowest dose of

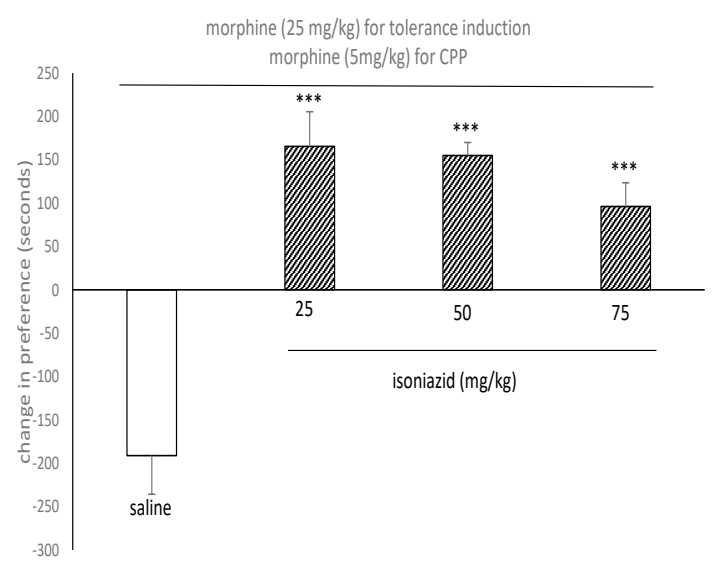

NEUR SCIENCE

Figure 3. Effects of Isoniazid on Tolerance Induction With the High-Dose of Morphine

Tolerance was induced in three groups of mice by the injection of the high dose of morphine $(25 \mathrm{mg} / \mathrm{kg})$ twice a day for four days. One hour before the administration of the high doses of morphine, these groups of mice received the different doses of isoniazid $(25,50$, and $75 \mathrm{mg} / \mathrm{kg}$, IP). On the fifth day of the experiment, the CPP was induced by an effective dose of morphine. Each point shows the Mean \pm SEM of the change in preference for eight mice;

*** $\mathrm{P}<0.001$ compared with the saline control group.

isoniazid (25 mg/kg) had the highest tolerance-preventive effect. Moreover, the measurement of the locomotor activity on the test day showed no significant difference in the locomotor activity among the different groups $\left(\mathrm{F}_{3,24}=1.47, \mathrm{P}=0.247\right)$.

\subsection{Isoniazid effects on the induction of sensitiza- tion with the effective dose of morphine}

Isoniazid injection $(25,50$, and $75 \mathrm{mg} / \mathrm{kg}$, IP) one hour before the administration of morphine $(5 \mathrm{mg} / \mathrm{kg}, \mathrm{SC}$ once a day for three days) prevented the acquisition of sensitization in three groups of mice compared with the saline-treated group $\left(\mathrm{F}_{7,56}=8.05, \mathrm{P}<0.001\right)$ (Figure 4). Again, the lowest dose of isoniazid inhibited the morphine sensitization more effectively compared with the other doses of isoniazid. On the other hand, the one-way ANOVA indicated no significant change in the locomotor activity on the test day $\left(\mathrm{F}_{7,56}=1.66, \mathrm{P}=0.138\right)$.

\section{Discussion}

The present research aimed to evaluate the effects of isoniazid on the tolerance and sensitization to the rewarding effects of morphine. Both tolerance and sensi- 


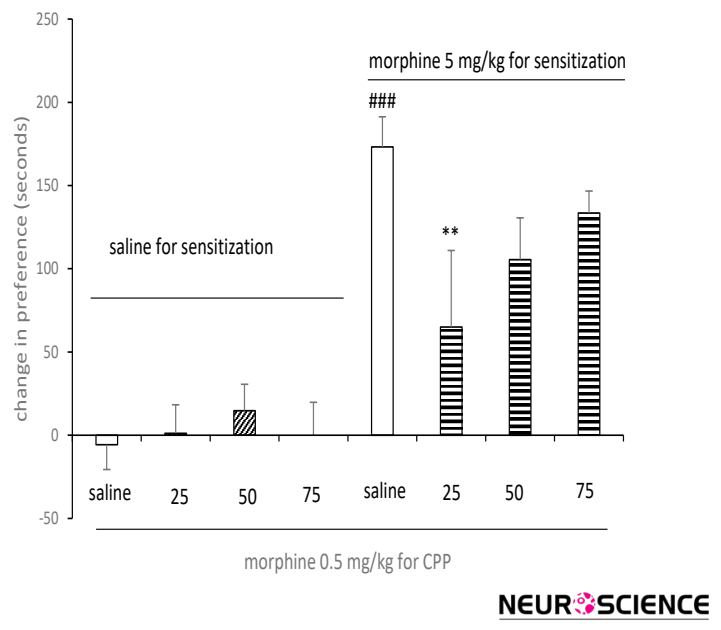

Figure 4. Effects of Isoniazid on the Acquisition of Sensitization to Morphine or Saline

One hour after the administration of isoniazid $(25,50$, and $75 \mathrm{mg} / \mathrm{kg}$, IP) to three groups of mice, the animals received an effective dose of morphine $(5 \mathrm{mg} / \mathrm{kg}$, SC). Three other groups of mice received saline $(10 \mathrm{~mL} / \mathrm{kg})$, one hour after the administration of the same doses of isoniazid. After a 5-day interval, the induction of CPP carried out with the ineffective dose of morphine $(0.5 \mathrm{mg} / \mathrm{kg})$, for all the animals Each point shows the Mean \pm SEM of the change in preference for eight mice;

** $\mathrm{P}<0.01$ compared with the morphine control group;

\#\#\# $\mathrm{P}<0.001$ compared with the saline control group.

tization as the habit-forming phenomena play important roles in drug-taking behavior in the long term. The first part of the experiments, as a basis for the other experiments, showed that morphine could induce a significant CPP in mice. The result indicates the rewarding effects of morphine because the CPP paradigm is a well-known procedure for the evaluation of the rewarding effects of drugs (Tzschentke, 1998). This finding agrees with many previous experiments showing that morphine could induce CPP in both sexes of different rodents or non-rodents (Bardo \& Bevins, 2000; Tzschentke, 1998; Wang et al., 2012). In our experiments, $5 \mathrm{mg} / \mathrm{kg}$ (SC) of morphine led to the highest conditioning scores.

This dose differs from the effective dose for the induction of CPP reported in some previous research (Do Couto, Aguilar, Manzanedo, Rodriguez-Arias, \& Minarro, 2003; Manzanedo, Aguilar, Rodríguez-Arias, \& Miñarro, 2001). The discrepancies can be ascribed to the differences in the conditioning procedures, the strain of animals, and the apparatus that were used by the other research teams.
The morphine-treated and saline-treated animals did not significantly differ in the locomotor activity, on the test day. Thus, the difference in the conditioning scores has not resulted from the morphine's effects on the locomotor activity of the animals. Also, the administration of the different doses of isoniazid induced no CPP or CPA to the drug-paired compartment. To the best of our knowledge, it is the first time that isoniazid has been used as a conditioning stimulus in place preference/aversion paradigm. Isoniazid at high doses inhibits GABA synthesis and depletes the GABA contents of the brain. Consequently, this drug can induce seizures by inhibiting GABA transmission (Asehinde et al., 2018; Patil et al., 2011). However, we used low doses of isoniazid that unlike the high doses can increase the GABA levels in the brain (Perry \& Hansen, 1973). Hence, low-dose isoniazid can act as an indirect GABA agonist. The GABAergic drugs diversely affect the place conditioning. Some of these agents did not induce CPP, while others produced place preference or even place aversion (Tzschentke, 1998). Therefore, GABAergic agents have complicated effects on the reward.

In the next phase of the present research, it was shown that the administration of isoniazid before morphine inhibits the induction of tolerance to the rewarding effects of morphine. In line with our results, previous research showed that topiramate (acting as an agonist of the GABAA and GABAB receptors) inhibited the acquisition of tolerance to the locomotor-activating effects of high-dose morphine (Javadzadeh et al., 2017). Also, it was found that the administration of GABAergic agents into the central nucleus of the amygdala modulated the acquisition and expression of morphine tolerance in rats (Alavian \& Ghiasvand, 2017). Furthermore, the different GABAergic agents have different effects on tolerance to the analgesic effects of morphine (Sivam \& Ho, 1985). The release of dopamine by morphine is a dose-dependent process, and the effects of morphine on dopamine release seems to be biphasic (Maisonneuve, Warner, \& Glick, 2001).

On the other hand, the induction of tolerance increases the basal dopamine levels in the nucleus accumbens (Johnson \& Glick, 1993). By binding to the mu-opioid receptors on the GABAergic interneurons of VTA (ventral tegmental area), morphine inhibits these neurons and removes the inhibition of the dopaminergic neurons of the VTA. Consequently, the dopamine release increases in the nucleus accumbens (Maisonneuve et al., 2001; Xi $\&$ Stein, 2002). It seems that the pretreatment with isoniazid decreases the amount of dopamine release with high doses of morphine by increasing the GABAergic tone in the VTA. Therefore, morphine could not induce tolerance. 
Consistent with this speculation, the administration of an indirect GABA agonist ( $\gamma$-vinyl-GABA) into the VTA, but not into the nucleus accumbens, prevented heroin self-administration (Xi \& Stein, 2000); the elevation of GABA by these agents likely inhibited the heroin-induced dopamine release in the nucleus accumbens (Gerasimov et al., 1999).

Sensitization to the effects of morphine is mediated through the different brain regions and neurotransmitter systems (Aguilar, Manzanedo, Do Couto, Rodríguez-Arias, \& Miñarro, 2009; Chefer \& Shippenberg, 2009; Farahmandfar, Zarrindast, Kadivar, Karimian, \& Naghdi, 2011; Fu et al., 2012; Listos et al., 2016; Manzanedo, Aguilar, Do Couto, Rodríguez-Arias, \& Miñarro, 2009; Sahraei et al., 2006; Vigano et al., 2003). the GABAergic system is among the neurotransmitter systems with an important role in the sensitization. This statement is supported by studies on laboratory animals indicating the alteration of morphine-induced behavioral sensitization by the administration of GABAergic agents (Bartoletti, Ricci, \& Gaiardi, 2007; Fu et al., 2012; Zarrindast et al., 2007). On the other hand, the induction of morphine sensitization could alter the effects of morphine on the GABA levels in the sensitized animals (Farahmandfar et al., 2011).

The present results showed that the isoniazid pretreatment abolished the influence of the effective dose of morphine on the induction of sensitization. One may speculate that isoniazid by increasing the brain's GABA levels may prevent the effects of morphine in decreasing GABA levels in the VTA. Therefore, during the induction of sensitization, the effective dose of morphine could not induce dopamine release in the nucleus accumbens, thus, it could not induce sensitization. Consistent with this hypothesis, the administration of GABAB agonist (baclofen) inhibited the development and expression of morphine-induced behavioral sensitization in rats, by decreasing dopamine levels in the nucleus accumbens $(\mathrm{Fu}$ et al., 2012). Also, the administration of gamma-vinyl GABA (an irreversible GABA-transaminase) before heroin inhibited the heroin-induced dopamine release in the nucleus accumbens of rats (Gerasimov et al., 1999).

However, it seems to be a raw idea: on one hand, the GABAergic system is widely dispersed in the brain (Hampe, Mitoma, \& Manto, 2017); on the other hand, different brain regions may be involved in the sensitization (Etemadi et al., 2004; Farahmandfar et al., 2011). Therefore, considering the systemic administration of isoniazid in the present investigation, we cannot conclusively attribute the effects of the isoniazid on morphine sensitization to its effects on a single region of the brain.
The use of direct or indirect GABA agonists have shown promising results in the treatment of the alcohol, cocaine, nicotine, and opiate addictions (Brebner, Ahn, \& Phillips, 2005; Brodie, Figueroa, \& Dewey, 2003; Cousins, Roberts, \& de Wit, 2002; Di Ciano \& Everitt, 2003; Peng et al., 2008; Xi \& Stein, 2000). In the present study, isoniazid effectively prevented tolerance and sensitization to the rewarding effects of morphine. The isoniazid doses used in the present research were relatively low. In conclusion, it seems that isoniazid, at least in part, is a useful agent for the treatment of morphine addiction. More investigations are required before isoniazid can be used in the treatment of diseases other than tuberculosis.

\section{Ethical Considerations}

\section{Compliance with ethical guidelines}

A Local Institutional Animal Care and use committee at the University of Maragheh monitored the animals' maintenance conditions and approved the animal experiment protocol (Ethical Code: UM-2018-number 21).

\section{Funding}

This article is Part Of A Research Project Supported by the University of Maragheh Research Affairs Office.

\section{Authors' contributions}

Conceptualization, methodology, data analysis, writing the original draft: Amir Abbas Barzegari; Conducting the experiments on laboratory animals: Kamran Shahabi

\section{Conflict of interest}

There is no conflict of interest to declare.

\section{Acknowledgments}

Hereby, we sincerely thank all those who helped us to set up the animal house of the University of Maragheh for animal experiments. Our special thanks go to Dr Arash Khorrami, Vice-Chancellor for Food and Drug at Maragheh University of Medical Sciences for his friendly cooperation in providing morphine ampoules for the present research. 


\section{References}

Aguilar, M. A., Manzanedo, C., Do Couto, B. R., Rodríguez-Arias, M., \& Miñarro, J. (2009). Memantine blocks sensitization to the rewarding effects of morphine. Brain Research, 1288, 95-104. [DOI:10.1016/j.brainres.2009.06.100] [PMID]

Alavian, F., \& Ghiasvand, S. (2017). GABAB receptors within the central nucleus of amygdala may involve in the morphine-induced incentive tolerance in female rats. Iranian Journal of Basic Medical Sciences, 20(7), 822-28. [DOI:10.22038/ IJBMS.2017.9018]

Asehinde, S., Ajayi, A., Bakre, A., Omorogbe, O., Adebesin, A., \& Umukoro, S. (2018). Effects of Jobelyn ${ }^{\circledR}$ on Isoniazid-Induced Seizures, Biomarkers of Oxidative Stress and Glutamate Decarboxylase Activity in Mice. Basic and Clinical Neuroscience, 9(6), 389-96. [DOI:10.32598/bcn.9.6.389] [PMID] [PMCID]

Azizi, P., Haghparast, A., \& Hassanpour-Ezatti, M. (2009). Effects of CB1 receptor antagonist within the nucleus accumbens on the acquisition and expression of morphine-induced conditioned place preference in morphine-sensitized rats. Behavioural Brain Research, 197(1), 119-24. [DOI:10.1016/j. bbr.2008.08.009] [PMID]

Bardo, M., \& Bevins, R. A. (2000). Conditioned place preference: what does it add to our preclinical understanding of drug reward? Psychopharmacology (Berl), 153(1), 31-43. [DOI:10.1007/ s002130000569] [PMID]

Bartoletti, M., Ricci, F., \& Gaiardi, M. (2007). A GABA B agonist reverses the behavioral sensitization to morphine in rats. Psychopharmacology (Berl), 192(1), 79-85. [DOI:10.1007/s00213006-0693-8] [PMID]

Binswanger, I. A., Blatchford, P. J., Mueller, S. R., \& Stern, M F. (2013). Mortality after prison release: Opioid overdose and other causes of death, risk factors, and time trends from 1999 to 2009. Annals of Internal Medicine 159(9), 592-600. [DOI:10.7326/0003-4819-159-9-201311050-00005] [PMID] [PMCID]

Brebner, K., Ahn, S., \& Phillips, A. G. (2005). Attenuation of d-amphetamine self-administration by baclofen in the rat: Behavioral and neurochemical correlates. Psychopharmacology (Berl), 177(4), 409-17. [DOI:10.1007/s00213-004-1968-6] [PMID]

Brodie, J. D., Figueroa, E., \& Dewey, S. L. (2003). Treating cocaine addiction: From preclinical to clinical trial experience with $\gamma$-vinyl GABA. Synapse, 50(3), 261-5. [DOI:10.1002/ syn.10278] [PMID]

Chefer, V., \& Shippenberg, T. (2009). Augmentation of morphine-induced sensitization but reduction in morphine tolerance and reward in delta-opioid receptor knockout mice. Neuropsychopharmacology, 34(4), 887. [DOI:10.1038/npp.2008.128] [PMID] [PMCID]

Compton, W. M., \& Volkow, N. D. (2006). Major increases in opioid analgesic abuse in the United States: Concerns and strategies. Drug and Alcohol Dependence Journal, 81(2), 103-7. [DOI:10.1016/j.drugalcdep.2005.05.009] [PMID]

Cousins, M. S., Roberts, D. C., \& de Wit, H. (2002). GABAB receptor agonists for the treatment of drug addiction: A review of recent findings. Drug and Alcohol Dependence Journal, 65(3), 209-20. [DOI:10.1016/S0376-8716(01)00163-6]
Di Ciano, P., \& Everitt, B. J. (2003). The GABA B receptor agonist baclofen attenuates cocaine-and heroin-seeking behavior by rats. Neuropsychopharmacology, 28(3), 510. [DOI:10.1038/ sj.npp.1300088] [PMID]

Do Couto, B. R., Aguilar, M., Manzanedo, C., Rodriguez-Arias, M., \& Minarro, J. (2003). Reinstatement of morphine-induced conditioned place preference in mice by priming injections. Neural Plasticity, 10(4), 279-90. [DOI:10.1155/NP.2003.279] [PMID] [PMCID]

Etemadi, L., Sahraei, H. E. D. A. Y. A. T., Ghoshooni, H., Oryan, S., Eidi, M., \& Eidi, A. (2004). The effect of GABAB receptor activation within the ventral tegmental area on morphine-induced incentive sensitization in female rats. Iranian Journal of Pharmaceutical Research, 3(Supplement 1), 32-2. [DOI:10.22037/ijpr.2010.121]

Farahmandfar, M., Zarrindast, M. R., Kadivar, M., Karimian, S. M., \& Naghdi, N. (2011). The effect of morphine sensitization on extracellular concentrations of GABA in dorsal hippocampus of male rats. European Journal of Pharmacology, 669(1-3), 66-70. [DOI:10.1016/j.ejphar.2011.07.050] [PMID]

Fu, Z., Yang, H., Xiao, Y., Zhao, G., \& Huang, H. (2012). The gammaaminobutyric acid type $B$ (GABA B) receptor agonist baclofen inhibits morphine sensitization by decreasing the dopamine level in rat nucleus accumbens. Behavioural Brain Research, 8(1), 20. [DOI:10.1186/1744-9081-8-20] [PMID] [PMCID]

Gerasimov, M. R., Ashby Jr, C. R., Gardner, E. L., Mills, M. J., Brodie, J. D., \& Dewey, S. L. (1999). Gamma-vinyl GABA inhibits methamphetamine, heroin, or ethanol-induced increases in nucleus accumbens dopamine. Synapse, 34(1), 11-9. [DOI:10.1002/(SICI)1098-2396(199910)34:13.0.CO;2-5]

Gupta, G., Dua, K., Kazmi, I., \& Anwar, F. (2014). Anticonvulsant activity of Morusin isolated from Morus alba: Modulation of GABA receptor. Biomedicine \& Aging Pathology, 4(1), 29-32. [DOI:10.1016/j.biomag.2013.10.005]

Hampe, C. S., Mitoma, H., \& Manto, M. (2017). GABA and Glutamate: Their transmitter role in the CNS and pancreatic islets. In: J. Samardzic, (Editor), Molecular Neuroscience. London: Intechope. [DOI:10.5772/intechopen.70958]

Javadzadeh, S., Sahraei, H., Khosravi, M., Ghoshooni, H., Fatemi, S. M., \& Shams, J., et al. (2017). Dual effects of topiramate on tolerance to morphine-induced locomotors activity in small laboratory male mice. Trauma Monthly, 22(01), 267-73. https:// www.researchgate.net/publication/266391544

Johnson, D. W., \& Glick, S. D. (1993). Dopamine release and metabolism in nucleus accumbens and striatum of morphinetolerant and nontolerant rats. Pharmacol Biochem Behav, 46(2), 341-7. [DOI:10.1016/0091-3057(93)90362-W]

Katzung, B. G. (Ed). (2017). Basic and clinical pharmacology. $14^{\text {th }}$ ed San Francisco: McGraw-Hill Education.

Koob, G. F., \& Le Moal, M. (2001). Drug addiction, dysregulation of reward, and allostasis. Neuropsychopharmacology, 24(2), 97129. [DOI:10.1016/S0893-133X(00)00195-0]

Listos, J., Talarek, S., Listos, P., Orzelska, J., Łupina, M., \& Fidecka, S. (2016). Effects of the adenosinergic system on the expression and acquisition of sensitization to conditioned place preference in morphine-conditioned rats. Naunyn-Schmiedeberg's Archives of Pharmacology, 389(2), 233-41. [DOI:10.1007/s00210-015-1190-6] [PMID] [PMCID] 
Lorenz, T. H., Calden, G., \& Ousley, J. L. (1953). A study of the effects of isoniazid on the emotions of tuberculous patients. The American Review of Tuberculosis, 68(4), 523-34.

Maisonneuve, I. M., Warner, L. M., \& Glick, S. D. (2001). Biphasic dose-related effects of morphine on dopamine release Drug and Alcohol Dependence, 65(1), 55-63. [DOI:10.1016/ S0376-8716(01)00150-8]

Manzanedo, C., Aguilar, M. A., Do Couto, B. R., RodríguezArias, M., \& Miñarro, J. (2009). Involvement of nitric oxide synthesis in sensitization to the rewarding effects of morphine. Neuroscience Letters, 464(1), 67-70. [DOI:10.1016/j.neulet.2009.08.017] [PMID]

Manzanedo, C., Aguilar, M. A. A., Rodríguez-Arias, M., \& Miñarro, J. (2001). Effects of dopamine antagonists with different receptor blockade profiles on morphine-induced place preference in male mice. Behavioural Brain Research, 121(1-2), 189-97. [DOI:10.1016/S0166-4328(01)00164-4]

McCabe, S. E., West, B. T., \& Boyd, C. J. (2013). Leftover prescription opioids and nonmedical use among high school seniors: A multi-cohort national study.Journal of Adolescent Health, 52(4), 480-5. [DOI:10.1016/j.jadohealth.2012.08.007] [PMID] [PMCID]

Nau, R., Sörgel, F., \& Eiffert, H. (2010). Penetration of drugs through the blood-cerebrospinal fluid/blood-brain barrier for treatment of central nervous system infections. Clinical Microbiology Reviews, 23(4), 858-83. [DOI:10.1128/CMR.0000710] [PMID] [PMCID]

Negus, S. S., \& Miller, L. L. (2014). Intracranial self-stimulation to evaluate abuse potential of drugs. Pharmacological Reviews, 66(3), 869-917. [DOI:10.1124/pr.112.007419] [PMID] [PMCID]

Patil, M. S., Patil, C., Patil, S., \& Jadhav, R. (2011). Anticonvulsant activity of aqueous root extract of Ficus religiosa. Journal of Ethnopharmacology, 133(1), 92-6. [DOI:10.1016/j. jep.2010.09.004] [PMID]

Peng, X. Q., Li, X., Gilbert, J. G., Pak, A. C., Ashby Jr, C. R., \& Brodie, J. D., et al. (2008). Gamma-vinyl GABA inhibits cocainetriggered reinstatement of drug-seeking behavior in rats by a non-dopaminergic mechanism. Drug and Alcohol Dependence 97(3), 216-25. [DOI:10.1016/j.drugalcdep.2007.10.004] [PMID] [PMCID]

Perry, T., \& Hansen, S. (1973). Sustained drug-induced elevation of brain gaba in the rat. Journal of Neurochemistry, 21(5), 1167-75. [DOI:10.1111/j.1471-4159.1973.tb07572.x] [PMID]

Perry, T., Urquhart, N., Hansen, S., \& Kennedy, J. (1974). $\mathrm{Y}$-Aminobutyric acid: Drug-induced elevation in monkey brain. Journal of Neurochemistry, 23(2), 443-5. [DOI:10.1111/j.1471-4159.1974.tb04378.x] [PMID]

Perry, T. L., Wright, J. M., Hansen, S., \& MacLeod, P. M. (1979). Isoniazid therapy of Huntington disease. Neurology, 29(3), 370-5. [DOI:10.1212/WNL.29.3.370] [PMID]

Robinson, T. E., \& Berridge, K. C. (1993). The neural basis of drug craving: An incentive-sensitization theory of addiction Brain Research Reviews, 18(3), 247-91. [DOI:10.1016/01650173(93)90013-P]

Sahraei, H., Aliabadi, A. A., Zarrindast, M. R., Ghoshooni, H., Nasiri, A., \& Barzegari-Sorkheh, A. A., et al. (2007). Ascorbic acid antagonizes nicotine-induced place preference and be- havioral sensitization in mice. European Journal of Pharmacology, 560(1), 42-8. [DOI:10.1016/j.ejphar.2006.12.019] [PMID]

Sahraei, H., Barzegari, A. A., Shams, J., Zarrindast, M. R., Haeri-Rohani, A., \& Ghoshooni, H., et al. (2006). Theophylline inhibits tolerance and sensitization induced by morphine: A conditioned place preference paradigm study in female mice. Behavioural Pharmacology, 17(7), 621-8. [DOI:10.1097/01. fbp.0000236274.18042.54] [PMID]

Salzer, H. M., \& Lurie, M. L. (1953). Anxiety and depressive states treated with isonicotinyl hydrazide (isoniazid). AMA Archives of Neurology and Psychiatry, 70(3), 317-24. [DOI:10.1001/archneurpsyc.1953.02320330042005] [PMID]

Shi, R., Itagaki, N., \& Sugawara, I. (2007). Overview of anti-tuberculosis (TB) drugs and their resistance mechanisms. MiniReviews in Medicinal Chemistry, 7(11), 1177-85. [DOI:10.2174/1 38955707782331740] [PMID]

Sivam, S., \& Ho, I. (1985). GABA in morphine analgesia and tolerance. Life Sciences, 37(3), 199-208. [DOI:10.1016/00243205(85)90645-9]

Stewart, J., \& Badiani, A. (1993). Tolerance and sensitization to the behavioral effects of drugs. Behavioural Pharmacology. 4(4):289-312 [DOI:10.1097/00008877-199308000-00003] [PMID]

Tzschentke, T. M. (1998). Measuring reward with the conditioned place preference paradigm: A comprehensive review of drug effects, recent progress and new issues. Progress in Neurobiology, 56(6), 613-72. [DOI:10.1016/S0301-0082(98)00060-4]

Van Ree, J. M., Gerrits, M. A., \& Vanderschuren, L. J. (1999). Opioids, reward and addiction: an encounter of biology, psychology, and medicine. Pharmacological Reviews, 51(2), 341-96. https:// pharmrev.aspetjournals.org/content/51/2/341.short

Vigano, D., Rubino, T., Di Chiara, G., Ascari, I., Massi, P., \& Parolaro, D. (2003). $\mu$ opioid receptor signaling in morphine sensitization. Neuroscience, 117(4), 921-9. [DOI:10.1016/S03064522(02)00825-4]

Wang, J., Wu, X., Li, C., Wei, J., Jiang, H., \& Liu, C., et al. (2012). Effect of morphine on conditioned place preference in rhesus monkeys. Addiction Biology, 17(3), 539-46. [DOI:10.1111/ j.1369-1600.2010.00289.x] [PMID]

Xi, Z.-X., \& Stein, E. A. (2000). Increased mesolimbic GABA concentration blocks heroin self-administration in the rat. Journal of Pharmacology and Experimental Therapeutics, 294(2), 613-9. https://jpet.aspetjournals.org/content/294/2/613.short

Xi, Z.X., \& Stein, E. A. (2002). GABAergic mechanisms of opiate reinforcement. Alcohol and Alcoholism, 37(5), 485-94. [DOI:10.1093/alcalc/37.5.485] [PMID]

Zarrindast, M. R., Heidari-Darvishani, A., Rezayof, A., FathiAzarbaijani, F., Jafari-Sabet, M., \& Hajizadeh-Moghaddam, A. (2007). Morphine-induced sensitization in mice: Changes in locomotor activity by prior scheduled exposure to GABAA receptor agents. Behavioural Pharmacology, 18(4), 303-10. [DOI:10.1097/FBP.0b013e3282186baa] [PMID]

Zarrindast, M. R., \& Rezayof, A. (2007). Morphine-induced place preference: Interactions with neurotransmitter systems Iranian Journal of Pharmaceutical Research, 6(1), 3-15. [DOI: 10.22037/IJPR.2010.693] 